\title{
Susceptibility to desferrioxamine: a new test for the identification of Staphylococcus epidermidis
}

\author{
J. A. LINDSAY and T. V. RILEY
}

Department of Microbiology, University of Western Australia and Sir Charles Gairdner Hospital, Queen Elizabeth /I Medical Centre, Nedlands 6009, Western Australia

\begin{abstract}
Summary. The ability to identify Staphylococcus epidermidis quickly and accurately has become increasingly important in clinical microbiology. Susceptibility to desferrioxamine, an iron-chelating agent, was investigated as a new test for the identification of S. epidermidis. All strains of $S$. epidermidis and $S$. hominis tested were susceptible to a $1000-\mu \mathrm{g}$ disk of desferrioxamine when grown on brain heart infusion agar. All other strains of coagulasenegative staphylococci, $S$. aureus and micrococci were resistant. As a single test, susceptibility to desferrioxamine was $96.4 \%$ efficient in identifying S. epidermidis; when combined with additional tests such as alkaline phosphatase production and fermentation of trehalose, the efficiency improved to $100 \%$. Desferrioxamine disks were easy to prepare, stable and inexpensive. The test was simple to perform and interpret and should readily find application in clinical microbiology laboratories.
\end{abstract}

\section{Introduction}

Coagulase-negative staphylococci (CNS) have become recognised increasingly as a cause of nosocomial infections, particularly bacteraemia associated with indwelling central venous catheters ${ }^{1,2}$ and peritonitis associated with continuous ambulatory peritoneal dialysis (CAPD) ${ }^{3,4}$ The species of CNS most commonly isolated from human clinical specimens has been identified as Staphylococcus epidermidis, with a frequency of $72^{5}-92 \%{ }^{1}$ Conventional methods of identifying $S$. epidermidis, such as that of Kloos and Schleifer, ${ }^{6}$ are considered to be too slow and unsuitable for routine clinical microbiology laboratories. ${ }^{7}$ Many commercially available miniaturised systems are also slow, have a limited database, lack specificity ${ }^{7}$ and are expensive.

Desferrioxamine is a siderophore, synthesised by Streptomyces pilosus and used clinically in the treatment of acute and chronic iron overload. ${ }^{8}$ Studies of the effects of desferrioxamine on bacterial growth in vitro and in vivo have produced conflicting results. With some Neisseria spp. and Listeria monocytogenes, for example, desferrioxamine inhibited growth, whereas growth of Salmonella typhimurium, Klebsiella spp. and Yersinia enterocolitica was stimulated. ${ }^{9}$ When we investigated the effects of desferrioxamine on CNS, only the growth of $S$. epidermidis and $S$. hominis was inhibited, suggesting that inhibition of growth by desferrioxamine may form the basis of a simple test for the identification of these organisms.

\section{Materials and methods}

\section{Bacterial strains}

The 95 isolates of CNS studied were from blood samples submitted for culture to the Clinical Microbiology Department, Sir Charles Gairdner Hospital, Perth, Western Australia. They were identified by either the API-Staph strip (API System, Montalieu Vercieu, France) or the Vitek GPI Card (Vitek Systems, Hazelwood, MO, USA) and comprised 57 S. epidermidis isolates, $13 S$. haemolyticus, six $S$. warneri, five $S$. simulans, four $S$. hominis, four $S$. capitis, three $S$. saprophyticus, two $S$. cohnii and one $S$. auricularis. Isolates were stored at $-70^{\circ} \mathrm{C}$ in brain heart infusion broth with glycerol $20 \%$ added.

For comparative purposes 10 clinical isolates of $S$. aureus and six reference cultures-S. epidermidis NCTC 14990, Micrococcus luteus NCTC nos. 7743 and 2665, M. varians NCTC nos. 8340 and 7944 and $M$. roseus NCTC 7520 were also investigated.

\section{Reagents}

Desferrioxamine B mesylate (Desferal; Ciba-Geigy Ltd, Lane Cove, Australia) was obtained from the Pharmacy Department, Sir Charles Gairdner Hospital. A $0.5 \mathrm{~g}$ vial was reconstituted with $5 \mathrm{ml}$ of sterile distilled water to give a final concentration of $100 \mathrm{mg} /$ $\mathrm{ml}$.

\section{Minimum inhibitory concentrations ( $M I C s$ )}

MICs of desferrioxamine were determined by an agar dilution method. Brain Heart Infusion Agar 
(BHIA; Oxoid) plates were prepared containing $20 \mathrm{ml}$ of agar. Doubling dilutions of desferrioxamine up to 1 in 64 were prepared in sterile distilled water and $0 \cdot 1 \mathrm{ml}$ of each dilution was spread over a BHIA plate and allowed to absorb into the medium and equilibrate, giving a maximum final concentration of $500 \mu \mathrm{g} / \mathrm{ml}$.

The inoculum was prepared by diluting an overnight culture to the turbidity of a $0.5 \mathrm{McF}$ arland standard with sterile saline $0.85 \%$. The agar plates were inoculated with a ten-fold dilution of this suspension by means of a multipoint inoculator (Mast Laboratories Ltd, Liverpool) giving a final inoculum of $10^{4}$ bacteria per spot. The plates were incubated aerobically at $37^{\circ} \mathrm{C}$ for $18 \mathrm{~h}$. After incubation, the MIC was determined as the lowest concentration of desferrioxamine that caused maximum reduction in growth. Susceptible strains grew as a fine haze only, similar to that seen when testing for sulphonamide susceptibility, ${ }^{10}$ whereas resistant strains produced growth of a nature similar to that seen on a control plate containing no desferrioxamine.

\section{Disk-diffusion susceptibility testing}

As an agar dilution method of testing might be unsuitable for a routine laboratory, the test was modified to use 6-mm diameter filter-paper disks. In preliminary experiments, disks were prepared that contained $1 \mu \mathrm{g}, 10 \mu \mathrm{g}, 100 \mu \mathrm{g}$ and $1000 \mu \mathrm{g}$ of desferrioxamine and allowed to dry. BHIA, Blood Agar (Oxoid), Mueller-Hinton Agar (Oxoid) and Heart Infusion Agar (Gibco, Madison, USA) plates were spread-inoculated to produce an even lawn with a cotton swab and an inoculum of test organism prepared as described above. The disks containing different amounts of desferrioxamine were placed on each agar plate; the plates were incubated at $37^{\circ} \mathrm{C}$ for $18 \mathrm{~h}$ and the diameters of zones of inhibition were recorded. After these preliminary experiments, BHIA plates and $1000-\mu \mathrm{g}$ desferrioxamine disks were chosen for tests with all $95 \mathrm{CNS}$ isolates, the 10 clinical isolates of $S$. aureus and the reference strains of $S$. epidermidis and Micrococcus spp.

The stability of the prepared disks at room temperature (approximately $25^{\circ} \mathrm{C}$ ) and at $5^{\circ} \mathrm{C}$ was assessed by repeated testing of the representative group of CNS over a period of weeks and recording any variation in zone size.

\section{Additional tests}

The ability of $S$. epidermidis and $S$. hominis to produce alkaline phosphatase was assessed with a commercially available rapid test (Rosco Diagnostica, Taastrup, Denmark) according to the manufacturers' instructions. Briefly, a bacterial suspension (equivalent in turbidity to a 2 McFarland standard) was prepared in $0.25 \mathrm{ml}$ of saline $0.85 \%$ in an Eppendorf tube. One alkaline phosphatase tablet was added to the tube which was incubated at $37^{\circ} \mathrm{C}$ for $4 \mathrm{~h}$. A yellow colour was recorded as indicating a positive result, and a colourless result was recorded as negative.

The fermentation of trehalose was assessed by the purple agar plate method and the criteria of Kloos and Schleifer. ${ }^{6}$

\section{Results}

The susceptibility of 95 strains of CNS to desferrioxamine as assessed by the agar dilution method is shown in table I. None of the strains of $S$. haemolyticus, $S$. warneri, $S$. simulans, $S$. capitis, $S$. saprophyticus, $S$. cohnii and $S$. auricularis were inhibited by the highest concentration of desferrioxamine tested, $500 \mu \mathrm{g} / \mathrm{ml}$. All strains of $S$. epidermidis and $S$. hominis were inhibited at a concentration of $62.5 \mu \mathrm{g} / \mathrm{ml}$.

Table I. In-vitro susceptibility of CNS to desferrioxamine

\begin{tabular}{|c|c|c|c|c|c|c|c|}
\hline \multirow{2}{*}{$\begin{array}{l}\text { Species } \\
\text { (number tested) }\end{array}$} & \multicolumn{7}{|c|}{$\begin{array}{l}\text { Number of strains inhibited at the concen- } \\
\text { tration }(\mu \mathrm{g} / \mathrm{ml}) \text { indicated }\end{array}$} \\
\hline & $7 \cdot 8$ & $15 \cdot 6$ & $31 \cdot 2$ & $62 \cdot 5$ & 125 & 250 & 500 \\
\hline S. epidermidis (57) & 8 & 22 & 54 & 57 & 57 & 57 & 57 \\
\hline S. haemolyticus (13) & 0 & 0 & 0 & 0 & 0 & 0 & 0 \\
\hline S. warneri (6) & $\mathbf{0}$ & 0 & $\mathbf{0}$ & 0 & 0 & 0 & 0 \\
\hline S. simulans (5) & 0 & 0 & 0 & 0 & 0 & 0 & 0 \\
\hline S. hominis (4) & 1 & 3 & 4 & 4 & 4 & 4 & 4 \\
\hline S. capitis (4) & 0 & 0 & 0 & 0 & 0 & 0 & 0 \\
\hline S. saprophyticus (3) & 0 & 0 & 0 & 0 & 0 & 0 & 0 \\
\hline S. cohnii (2) & 0 & 0 & 0 & 0 & 0 & 0 & 0 \\
\hline S. auricularis (1) & 0 & 0 & 0 & 0 & $\mathbf{0}$ & 0 & 0 \\
\hline
\end{tabular}

The results of experiments to determine the suitability of a disk-diffusion susceptibility testing method are shown in table II. The three strains of $S$. epidermidis used were chosen because they represented the spectrum of MICs obtained for this species. The 1000$\mu \mathrm{g}$ disks gave zones $>20 \mathrm{~mm}$ for susceptible strains and no zone for resistant strains, and were chosen for further study.

Table II. Diameters of zones of inhibition of five CNS strains around disks containing various amounts of desferrioxamine

\begin{tabular}{|c|c|c|c|c|c|}
\hline \multirow{2}{*}{ Strain no. } & \multirow{2}{*}{$\begin{array}{c}\text { MIC } \\
(\mu \mathrm{g} / \mathrm{ml})\end{array}$} & \multicolumn{4}{|c|}{ Zone size $(\mathrm{mm})$ around disk } \\
\hline & & $1 \mu \mathrm{g}$ & $10 \mu \mathrm{g}$ & $100 \mu \mathrm{g}$ & $1000 \mu \mathrm{g}$ \\
\hline $\begin{array}{l}\text { S. epidermidis } 4415 \\
\text { S. epidermidis } 4416 \\
\text { S. epidermidis } 4434 \\
\text { S. simulans } 4417 \\
\text { S. capitis } 4413\end{array}$ & $\begin{array}{c}7 \cdot 8 \\
15 \cdot 6 \\
62 \cdot 5 \\
>500 \\
>500\end{array}$ & $\begin{array}{l}0 \\
0 \\
0 \\
0 \\
0\end{array}$ & $\begin{array}{c}7 \cdot 0 \\
6 \cdot 7 \\
8 \cdot 5 \\
0 \\
0\end{array}$ & $\begin{array}{c}16 \cdot 9 \\
15 \cdot 6 \\
18 \cdot 9 \\
0 \\
0\end{array}$ & $\begin{array}{c}21 \cdot 9 \\
21 \cdot 5 \\
25 \cdot 2 \\
0 \\
0\end{array}$ \\
\hline
\end{tabular}

All 95 CNS, 10 S. aureus and reference strains were tested for susceptibility by the disk diffusion method with the 1000- $\mu$ g desferrioxamine disks. All strains of 
S. epidermidis (including NCTC 14990) and S. hominis gave readable zones of inhibition whereas all other strains tested produced no zones of inhibition (table III).

Table III. Susceptibility of various staphylococci and micrococci to a $1000-\mu \mathrm{g}$ desferrioxamine disk

\begin{tabular}{lcc}
\hline & \multicolumn{2}{c}{ Zone diameters (mm) } \\
\cline { 2 - 3 } Species (number tested) & Mean & Range \\
& & \\
\hline S. epidermidis* (58) & $24 \cdot 8$ & $20 \cdot 5-29 \cdot 6$ \\
S. hominis (4) & $27 \cdot 3$ & $25 \cdot 8-28 \cdot 9$ \\
Other CNS (32) & $0 \dagger$ & 0 \\
S. aureus (10) & 0 & 0 \\
Micrococcus spp. (5) & 0 & 0 \\
& & \\
\hline
\end{tabular}

* Includes $S$. epidermidis NCTC 14990

$\uparrow$ No zones of inhibition observed.

If desferrioxamine susceptibility alone was used for the identification of $S$. epidermidis, the sensitivity of the test was $100 \%$, with specificity $92.5 \%$, a predictive value of a positive result of $93.1 \%$ and a predictive value of a negative result of $100 \%$. The overall efficiency of the desferrioxamine susceptibility test was $96.4 \%$.

To differentiate $S$. epidermidis from $S$. hominis, additional tests were performed (table IV): 50 of $57 S$. epidermidis isolates produced alkaline phosphatase and all $S$. hominis isolates fermented trehalose, as did one strain of $S$. epidermidis.

Table IV. Additional tests for the identification of $S$. epidermidis and $S$. hominis

\begin{tabular}{|c|c|c|c|c|}
\hline \multirow{2}{*}{$\begin{array}{l}\text { Species (number } \\
\text { tested) }\end{array}$} & \multicolumn{2}{|c|}{$\begin{array}{l}\text { Alkaline phospha- } \\
\text { tase production }\end{array}$} & \multicolumn{2}{|c|}{$\begin{array}{l}\text { Trehalose fermenta- } \\
\text { tion }\end{array}$} \\
\hline & Positive & Negative & Positive & Negative \\
\hline $\begin{array}{l}\text { S. epidermidis (57) } \\
\text { S. hominis (4) }\end{array}$ & $\begin{array}{r}50 \\
0\end{array}$ & $\begin{array}{l}7 \\
4\end{array}$ & $\begin{array}{l}1 \\
4\end{array}$ & $\begin{array}{r}56 \\
0\end{array}$ \\
\hline
\end{tabular}

The stability of the 1000- $\mu \mathrm{g}$ desferrioxamine disks over a 5-week period is shown in table V. There was no significant variation in zone diameters during the test period.

\section{Discussion}

The identification of CNS has assumed greater importance in recent years because of the increasing number of infections caused by these organisms. This is particularly relevant with blood cultures, in which CNS are also common contaminants, as the identification of $S$. epidermidis may be a guide to the clinical significance of an isolate. A simple, rapid, reliable and
Table V. Diameters of zones of inhibition of five CNS strains around $1000-\mu \mathrm{g}$ desferrioxamine disks after various weeks of storage

\begin{tabular}{|c|c|c|c|c|c|c|}
\hline \multirow{2}{*}{ Strain no. } & \multirow{2}{*}{$\begin{array}{c}\text { Temperature } \\
\left({ }^{\circ} \mathrm{C}\right) \\
\text { of storage }\end{array}$} & \multicolumn{5}{|c|}{ Zone size $(\mathrm{mm})$ at week } \\
\hline & & 0 & 1 & 2 & 3 & 5 \\
\hline S. epidermidis 4415 & $\begin{array}{c}\text { RT } \\
5^{\circ}\end{array}$ & $\begin{array}{c}21.9 \\
\ldots\end{array}$ & $\begin{array}{l}19.6 \\
21.6\end{array}$ & $\begin{array}{l}22.9 \\
23.6\end{array}$ & $\begin{array}{l}21 \cdot 8 \\
22 \cdot 1\end{array}$ & $\begin{array}{l}25 \cdot 6 \\
23 \cdot 8\end{array}$ \\
\hline S. epidermidis 4416 & $\begin{array}{c}\text { RT } \\
5^{\circ}\end{array}$ & $21 \cdot 5$ & $\begin{array}{l}20.0 \\
20.0\end{array}$ & $\begin{array}{l}21.4 \\
20.5\end{array}$ & $\begin{array}{l}21.8 \\
22.5\end{array}$ & $\begin{array}{l}25.4 \\
25.0\end{array}$ \\
\hline S. epidermidis 4434 & $\begin{array}{c}\text { RT } \\
5^{\circ}\end{array}$ & $25 \cdot 2$ & $\begin{array}{l}19.6 \\
20.5\end{array}$ & $\begin{array}{l}20.9 \\
18.9\end{array}$ & $\begin{array}{l}20.4 \\
19 \cdot 6\end{array}$ & $\begin{array}{l}25 \cdot 5 \\
22.9\end{array}$ \\
\hline S. simulans 4417 & $\begin{array}{c}\text { RT } \\
5^{\circ}\end{array}$ & $\begin{array}{c}0 \\
\ldots\end{array}$ & $\begin{array}{l}0 \\
0\end{array}$ & $\begin{array}{l}0 \\
0\end{array}$ & $\begin{array}{l}0 \\
0\end{array}$ & $\begin{array}{l}0 \\
0\end{array}$ \\
\hline S. capitis 4413 & $\begin{array}{c}\text { RT } \\
5^{\circ}\end{array}$ & $\begin{array}{c}0 \\
\ldots\end{array}$ & $\begin{array}{l}0 \\
0\end{array}$ & $\begin{array}{l}0 \\
0\end{array}$ & $\begin{array}{l}0 \\
0\end{array}$ & $\begin{array}{l}0 \\
0\end{array}$ \\
\hline
\end{tabular}

$\mathrm{RT}$, room temperature (c. $\left.25^{\circ} \mathrm{C}\right)$.

inexpensive test for the separation of $S$. epidermidis from other CNS is required.

Inhibition of growth by desferrioxamine offers such a test. In the present study, all strains of $S$. epidermidis were susceptible to a $1000-\mu \mathrm{g}$ desferrioxamine disk and all $S$. aureus, micrococci, and non-S. epidermidis strains, with the exception of $S$. hominis strains, were resistant. The test gave a predictive value for a positive result of $93.1 \%$ and a predictive value for a negative result of $100 \%$. If additional tests, such as alkaline phosphatase production and, more particularly, trehalose fermentation, were performed, the efficiency of the three tests in identifying $S$. epidermidis improved to $100 \%$.

Although only four strains of $S$. hominis were included in our series, previous investigations ${ }^{11}$ have successfully used trehalose fermentation to separate $S$. epidermidis from other CNS. However, the utility of phosphatase activity for this purpose has been more variable. In our study, $88 \%$ of the $57 \mathrm{~S}$. epidermidis strains produced alkaline phosphatase as detected by the Rosco Diagnostica 4-h tablet technique. However, five of the seven strains that gave negative results by this method had previously given a positive alkaline phosphatase result by the API-Staph strip, indicating that the detection of alkaline phosphatase in $S$. epidermidis depends on the method employed. This may explain the discrepancies between various studies with regard to phosphatase activity in S. epidermidis, from $7 \%$ negative in one study 5 to $30 \%$ negative in another. ${ }^{11}$

Various media were investigated for their suitability in the desferrioxamine disk test. Media that did not contain blood were superior to those containing blood and BHIA consistently gave good results. The unsuitability of media containing blood gives an indication of how the desferrioxamine disk test works. Unsupplemented bacteriological media contains up to $4 \mu \mathrm{M}$ iron $^{12}$ and this is usually adequate for the intrinsic iron requirement of most organisms. Once desferrioxamine is added to the medium it binds the iron to form 
ferrioxamine. It would appear that, as for some Neisseria spp. and L. monocytogenes, ${ }^{9}$ S. epidermidis cannot utilise the iron-containing form of desferrioxamine. However, in media supplemented with blood, either the iron-containing haemoglobin molecule is usable by $S$. epidermidis or the desferrioxamine is saturated and there is an excess of iron. Therefore, it is important that the desferrioxamine disk test be performed on culture media lacking blood or any other form of iron supplementation.

It is interesting to note that there was no correlation between zone size, at any disk concentration, and MIC of desferrioxamine for the three representative strains of $S$. epidermidis tested. This lack of correlation has been consistent for all isolates of $S$. epidermidis tested so far (results not shown) but cannot be explained.

A number of factors would suggest that the desferrioxamine disk test will prove to be extremely useful in the clinical laboratory. It can be performed easily with other disk tests for the rapid identification of staphylococci and micrococci from both blood

\section{References}

1. Sewell CM, Clarridge JE, Young EJ, Guthrie RK. Clinical significance of coagulase-negative staphylococci. $J$ Clin Microbiol 1982; 16: 236-239.

2. Bowman RA, Buck M. Staphylococcus hominis septicaemia in patients with cancer. Med $J$ Aust 1984; 140: 26-27.

3. Gokal R, Ramos JM, Francis DMA et al. Peritonitis in continuous ambulatory peritoneal dialysis. Lancet $1982 ; 2$ : 1388-1391.

4. West TE, Walshe JJ, Krol CP, Amsterdam D. Staphylococcal peritonitis in patients on continuous peritoneal dialysis. $J$ Clin Microbiol 1986; 23: 809-812.

5. Marsik FJ, Brake S. Species identification and susceptibility to 17 antibiotics of coagulase-negative staphylococci isolated from clinical specimens. J Clin Microbiol 1982; 15: 640645 .

6. Kloos WE, Schleifer KH. Simplified scheme for routine identification of human Staphylococcus species. $J$ Clin Microbiol 1975; 1: 82-88.

7. Pfaller MA, Herwaldt LA. Laboratory, clinical, and epidemio- cultures and urine samples. Blood cultures containing gram-positive cocci with appropriate morphology could be subcultured on to BHIA and both a Taxo A bacitracin disk added to separate micrococci from staphylococci ${ }^{13}$ and a desferrioxamine disk added to separate $S$. epidermidis from other staphylococci. Staphylococci from urine samples could be separated into $S$. epidermidis, $S$. saprophyticus and other CNS by the use of a 1000- $\mu \mathrm{g}$ desferrioxamine disk and a $5-\mu \mathrm{g}$ novobiocin disk. ${ }^{14}$

Desferrioxamine disks were readily prepared in the laboratory and showed no decrease in activity at $5^{\circ} \mathrm{C}$ or room temperature over a 5-week period.

In summary, susceptibility to a $1000-\mu$ g desferrioxamine disk will reliably separate $S$. epidermidis and $S$. hominis from other staphylococci and micrococci. When used with one or two additional tests, $S$. epidermidis alone may be identified with $100 \%$ efficiency. The test is cheap and simple to perform and should find application in the clinical diagnostic microbiology laboratory.

logical aspects of coagulase-negative staphylococci. Clin Microbiol Rev 1988; 1: 281-299.

8. Hartzen SH, Frimodt-Møller N, Thomsen VF. The antibacterial activity of a siderophore. APMIS 1989; 97: 419-424.

9. Robins-Browne RM, Prpic JK. Effects of iron and desferrioxamine on infections with Yersinia enterocolitica. Infect Immun 1985; 47: 774-779.

10. Ericsson HM, Sherris JC. Antibiotic sensitivity testing: report of an International Collaborative Study. Acta Pathol Microbiol Scand 1971; 217 Suppl: 1-90.

11. Stevens DL, Jones C. Use of trehalose-mannitol-phosphatase agar todifferentiate Staphylococcus epidermidis and Staphylococcus saprophyticus from other coagulase-negative staphylococci. J Clin Microbiol 1984; 20 : 977-980.

12. Weinberg ED. Iron and infection. Microbiol Rev 1978; 42: 4566.

13. Falk D, Guering SJ. Differentiation of Staphylococcus and Micrococcus spp. with the Taxo A bacitracin disk. J Clin Microbiol 1983; 18: 719-721.

14. McTaggart LA, Elliot TSJ. Is resistance to novobiocin a reliable test for confirmation of the identification of Staphylococcus saprophyticus? J Med Microbiol 1989; 30: 253-266. 